\title{
Plasma Haptoglobin Concentrations Are Elevated in Patients with Coronary Artery Disease
}

\author{
Chin-Wei Lee ${ }^{1}$, Tsai-Mu Cheng ${ }^{2}$, Chih-Pei Lin ${ }^{3,4}$, Ju-Pin Pan ${ }^{5,6^{*}}$ \\ 1 Division of Cardiology, Department of Medicine, Taipei Veterans General Hospital, Tao-Yuan Branch, Tao-Yuan, Taiwan, ROC, 2 Graduate Institute of \\ Translational Medicine, College of Medicine and Technology, Taipei Medical University, Taipei, Taiwan, ROC, 3 Biochemistry Section, Department of Pathology \\ and Laboratory Medicine, Taipei Veterans General Hospital, Taipei, Taiwan, ROC, 4 Institute of Biotechnology in Medicine, National Yang-Ming University, \\ Taipei, Taiwan, ROC, 5 Division of Cardiology, Department of Medicine, Taipei Veterans General Hospital, Taipei, Taiwan, ROC, 6 Faculty of Medicine, School \\ of Medicine, National Yang-Ming University, Taipei, Taiwan, ROC
}

\begin{abstract}
Inflammation underlies the development and progression of coronary artery plaques. Haptoglobin $(\mathrm{Hp})$ is an acute phase protein, the synthesis of which is increased during inflammation. The aim of this study was to investigate plasma $\mathrm{Hp}$ concentrations and phenotype in patients with coronary artery disease (CAD). We recruited 359 patients with fixed luminal stenosis $\geq 50 \%$ in at least one coronary artery (CAD group) and 83 patients with luminal stenosis $\leq 40 \%$, normal ejection fraction, and normal regional wall motion (control group). Plasma Hp concentrations were measured using a phenotype-specific enzyme-linked immunosorbent assay. Hp phenotype was determined by native polyacrylamide gel electrophoresis. Plasma lipid concentrations were measured. Plasma $\mathrm{Hp}$ concentrations were significantly higher in the CAD compared with the control group $(262.4 \pm 144.2$ vs $176.0 \pm 86.7 \mathrm{ng} / \mathrm{mL}, P<0.001)$; however, there was no between group difference in the distribution of $\mathrm{Hp}$ phenotype $(1-1=7.5 \%$ vs $7.2 \% ; 2-1=$ $40.4 \%$ vs $42.2 \% ; 2-2=52.1 \%$ vs $50.6 \%$ ). Stepwise multivariate logistic regression revealed that high $\mathrm{Hp}$ concentrations (odds ratio $[\mathrm{OR}]=5.865)$, male sex $(\mathrm{OR}=3.689)$, hypertension $(\mathrm{OR}=2.632)$, diabetes mellitus $(\mathrm{OR}=$ 3.300 ), and low-density lipoprotein concentrations $(O R=1.480)$ were independently associated with $C A D$ (all $P<0.05)$. Hp phenotype was not associated with CAD. Plasma Hp concentrations were significantly correlated with the severity of luminal stenosis $(r=0.236, P<0.001)$. Our findings suggest that plasma Hp concentrations may be elevated in patients with CAD. There does not appear to be any relationship between Hp phenotype and CAD.
\end{abstract}

Citation: Lee C-W, Cheng T-M, Lin C-P, Pan J-P (2013) Plasma Haptoglobin Concentrations Are Elevated in Patients with Coronary Artery Disease. PLoS ONE 8(10): e76817. doi:10.1371/journal.pone.0076817

Editor: Alice Y. W. Chang, Kaohsiung Chang Gung Memorial Hospital, Taiwan

Received April 29, 2013; Accepted August 28, 2013; Published October 9, 2013

Copyright: $\odot 2013$ Lee et al. This is an open-access article distributed under the terms of the Creative Commons Attribution License, which permits unrestricted use, distribution, and reproduction in any medium, provided the original author and source are credited.

Funding: This study was supported by grants from the Taipei Veterans General Hospital (VGH92-356 and VGH94-210, [J.P.P]) Taiwan, ROC. The funders had no role in study design, data collection and analysis, decision to publish, or preparation of the manuscript.

Competing interests: The authors have declared that no competing interests exist.

*E-mail: jppan@vghtpe.gov.tw

\section{Introduction}

Inflammation appears to play a key role in mediating coronary artery disease (CAD), a leading cause of death in the developed world [1]. Of note, a large body of evidence has demonstrated that inflammation plays a pivotal role in atherogenesis, unstable progression, and eventual disruption of atheroma plaques [2-4]. The mediators of this inflammation continue to be investigated in an effort to better understand the etiology, diagnosis, and treatment of CAD.

Haptoglobin $(\mathrm{Hp})$ is the major hemoglobin $(\mathrm{Hb})$ binding protein, as well as being an acute phase protein, the expression of which is increased during inflammation [5]. The primary function of $\mathrm{Hp}$ is the binding of extracorpuscular free $\mathrm{Hb}$, which attenuates the oxidative and inflammatory effects of $\mathrm{Hb}$ [6]. The $\mathrm{Hb}-\mathrm{Hp}$ complex is rapidly removed by the CD163 scavenger receptor on monocytes and macrophages [7]. Hp also exerts antioxidant effects by directly inhibiting the oxidation of low-density lipoprotein (LDL) [8]. There are two Hp alleles, $\mathrm{Hp} 1$ and 2 . In humans, homozygosity for the $\mathrm{Hp} 2$ allele is designated 2-2, homozygosity for the $\mathrm{Hp} 1$ allele is designated $1-1$, and heterozygosity for the $\mathrm{Hp}$ allele is designated 2-1 [6,9].

Current evidence concerning the relationship between $\mathrm{Hp}$ phenotypes and cardiovascular disease is inconclusive. Findings from an in vitro study suggest that $\mathrm{Hp} \mathrm{1-1}$ protein is superior to $\mathrm{Hp} 2-2$ protein in attenuating the oxidative action of $\mathrm{Hb}$ [10]. Further, the findings from an in vivo study revealed that atherosclerotic plaques from $\mathrm{Hp}$ 2-2 mice exhibited increased lipid peroxidation and macrophage accumulation, and contained more iron compared with plaques from $\mathrm{Hp} \mathrm{1-1}$ mice. This finding suggests that the $\mathrm{Hp}$ genotype may play a critical role in the oxidative and inflammatory response to intraplaque hemorrhage [11]. A number of reports concerning 
human studies have also indicated that the Hp 2-2 phenotype may be associated with an increased risk of myocardial infarction, stroke, and cardiovascular death [9,12-15]. In contrast, findings from the Framingham offspring cohort suggest that there is no relationship between $\mathrm{Hp}$ phenotype and the prevalence of coronary heart disease [16].

Although a number of studies have examined the $\mathrm{Hp}$ phenotype in the context of cardiovascular disease, no study date has examined the relationship between human plasma $\mathrm{Hp}$ concentrations and CAD. This may be because the purification process involved in the $\mathrm{Hp}$ immunoassay is challenging $[17,18]$. Of note, we have previously reported that plasma $\mathrm{Hp}$ concentrations are elevated in patients with abdominal aortic aneurysm (perhaps due to inflammation in the destructive elastic laminae of arteries) [19]. The aim of this study was to investigate plasma $\mathrm{Hp}$ concentrations and $\mathrm{Hp}$ phenotype in a cohort of Chinese patients with coronary artery disease (CAD).

\section{Methods}

\section{Study Participants}

The study participants were genetically unrelated patients of Chinese ancestry who were treated consecutively between January 2003 and December 2005 in the Division of Cardiology at Taipei Veterans General Hospital. All participants received coronary angiography (CAG) under the suspicion of coronary artery disease (CAD) with a positive thallium myocardial perfusion scan. All angiograms were independently evaluated by two medical imaging specialists who were unaware of the participants' medical histories. Multiple views from different angles were examined, and the degree of CAD was ascribed according to the coronary arterial segment with the most severe stenosis per the American Heart Association recommendations [20]. CAD was defined as a fixed stenotic lesion with luminal narrowing $\geq 50 \%$ in at least one of the major or minor coronary arteries. Patients who had luminal stenosis $\leq$ $40 \%$ (as determined by CAG), normal ejection fraction, and normal regional wall motion on left ventriculography were assigned to the control group. The left anterior descending artery, left circumflex artery, and right coronary artery were examined to evaluate the number of stenotic coronary arteries (none to three). All participants were free of unstable angina pectoris. Patients who had a documented myocardial infarction event within three months before undergoing coronary angiography were excluded. The study was approved by the Institutional Review Board of Taipei Veterans General Hospital. All patients who were enrolled in the study provided written informed consent.

\section{Clinical Chemistry}

Overnight fasting blood samples were obtained from all patients before catheterization and mixed with $0.1 \%$ ethylenediamine tetraacetic acid for measurement of total cholesterol, high-density lipoprotein (HDL), LDL, and triglyceride concentrations using standard techniques. Plasma C-reactive protein (CRP) concentrations were determined by IMMAGE high sensitivity CRP assay (Beckman Coulter, Inc, Fullerton, CA).

\section{Hp Phenotyping}

$\mathrm{Hp}$ phenotyping was carried out as previously described [21] using native polyacrylamide gel electrophoresis (PAGE) with hemoglobin-supplemented plasma. Briefly, overnight fasting blood samples were obtained from all patients before catheterization and mixed with $0.1 \%$ ethylenediamine tetraacetic acid. Plasma was isolated immediately by centrifuge then stored at $-20^{\circ} \mathrm{C} .7 \mu \mathrm{L}$ of plasma was premixed with $5 \mu \mathrm{L}$ of $8 \mathrm{mg} / \mathrm{mL}$ hemoglobin and equilibrated with $3 \mu \mathrm{L}$ of sample buffer $(0.625 \mathrm{~mol} / \mathrm{L}$ Tris-base, $\mathrm{pH} 6.8,50 \%$ glycerol $(\mathrm{v} / \mathrm{v})$, and $0.125 \mathrm{mg} / \mathrm{L}$ bromophenol blue). The mixture was run on a $7 \%$ native polyacrylamide gel $(\mathrm{pH} 8.8)$, with $5.5 \%$ polyacrylamide (26.5:1; acrylamide: bisacrylamide) used as a top stacking gel (pH 6.8). Electrophoresis was performed at an initial voltage of $120 \mathrm{~V}$, which was increased up to $150 \mathrm{~V}$ when the dye front reached the separating gel. After electrophoresis, the Hp-hemoglobin complex was visualized by shaking the gel in freshly prepared peroxidase substrate $\left(0.05 \% \quad 3,3^{\prime}\right.$ diaminobenzidine $[\mathrm{w} / \mathrm{v}]$ and $0.07 \%$ hydrogen peroxide $[\mathrm{v} / \mathrm{v}]$ in phosphate buffered saline). The results were confirmed by Western blotting using an a-chain specific monoclonal antibody.

\section{Hp Purification}

$\mathrm{Hp}$ was purified from plasma by chromatography on a mAbbased affinity column followed by high-performance liquate chromatography (HPLC) as described previously [18]. Briefly, 2 $\mathrm{mL}$ of filtered human plasma was loaded onto the antibody affinity-column (10 $\mathrm{mL}$ bed volume) at room temperature. The column was then washed with $50 \mathrm{~mL}$ of $20 \mathrm{mmol} / \mathrm{L}$ phosphate buffer containing $0.2 \mathrm{~mol} / \mathrm{L} \mathrm{NaCl}(\mathrm{pH} \mathrm{7.4})$, and then eluted with $50 \mathrm{~mL}$ of freshly prepared $0.15 \mathrm{~mol} / \mathrm{L} \mathrm{NaCl}$ solution $(\mathrm{pH} \mathrm{11)}$. Fractions $(5 \mathrm{~mL})$ were collected in tubes containing $0.25 \mathrm{~mL}$ of $1 \mathrm{~mol} / \mathrm{L}$ Tris- $\mathrm{HCl}$ buffer ( $\mathrm{pH} \mathrm{6.8)}$ to immediately neutralize the base. Pooled fractions containing $\mathrm{Hp}$ were then concentrated to a final volume of $1 \mathrm{~mL}$ using Centricon tubes (Millipore, Cork, Ireland) and filtered through a $0.45 \mu \mathrm{m}$ membrane. Gelfiltration HPLC with a Superose-12 column $(1 \times 30 \mathrm{~cm})$ (Pharmacia, Uppsala, Sweden) was then performed. The homogeneity of each isolated $\mathrm{Hp}$ type was greater than $95 \%$ as judged by sodium dodecyl sulfate-PAGE.

\section{Measurement of Human Free Hp Plasma Concentrations}

Human free Hp plasma concentrations were measured using a phenotype-matched standard sandwich enzyme-linked immunosorbent assay as described in our previous publication [18].

\section{Statistical Analysis}

Patients' demographic and clinical characteristics are summarized as mean \pm standard deviation for continuous data and number (percent) for categorical data. Continuous data were compared between groups by two-sample t-test or MannWhitney $U$, whereas categorical data were compared between groups by Pearson Chi-square test or Fisher's exact test. The optimal $\mathrm{Hp}$ concentration cut-off point for predicting CAD was 
determined based on maximization of the Youden index (Sensitivity+Specificity-1) using receiver operating characteristic (ROC) curve analysis. Pearson correlation analysis was performed to identify the correlation between $\mathrm{Hp}$ concentration and stenotic percentage and between $\mathrm{Hp}$ and CRP concentrations. Simple logistic regression analysis was performed to identify associations between participants' characteristics and CAD. Variables with significance $(P<0.05)$ in the simple logistic regression analysis were entered into multiple logistic regression analysis. Results are presented as estimated odds ratios (OR) with respective 95\% confidence intervals $(95 \% \mathrm{Cl})$ and $P$ values. All statistical assessments were two-tailed and considered significant if $P<0.05$. Statistical analyses were performed using SPSS 15.0 statistics software (SPSS Inc, Chicago, IL).

\section{Results}

A total of 442 participants, 359 in the CAD group and 83 in control group, were included in the study. Table 1 summarizes the baseline characteristics of these participants. Several baseline characteristics demonstrated significant between group differences. A significantly higher proportion of participants in the CAD group were men, had hypertension, had diabetes mellitus, were smokers, or took angiotensin converting enzyme inhibitors compared with participants in control group (all $P<0.05$ ). HDL concentrations were significantly lower and LDL and $\mathrm{Hp}$ concentrations were significantly higher in the CAD group compared with the control group (all $P<0.05$ ).

The Hp concentration cut-off for CAD, determined using ROC curve analysis (Figure 1), was found to be $288.4 \mathrm{ng} / \mathrm{mL}$ (specificity $=42.1 \%$; specificity $=90.4 \%$, positive predictive value $=95.0 \%$; negative predictive value $=90.4 \%$ ). On the basis of this findings, participants were categorized for further analysis as having low ( $\leq 288.4 \mathrm{ng} / \mathrm{mL})$ or high (> $288.4 \mathrm{ng} / \mathrm{mL})$ Hp concentrations.

Table 2 summarizes the participants' baseline characteristics by group and $\mathrm{Hp}$ concentration (low or high). Very few participants in the control group had high $\mathrm{Hp}$ concentrations. In both groups, participants with low $\mathrm{Hp}$ concentrations had significantly higher hemoglobin concentrations (both $P<0.05$ ). In the CAD group, there was a significant difference in the proportion of participants with different Hp phenotypes $(P<$ 0.001 ). Of note, a much higher proportion of participants with low $\mathrm{Hp}$ concentrations had the 1-1 Hp phenotype compared with participants with high $\mathrm{Hp}$ concentrations.

Overall, there was a significant positive correlation between $\mathrm{Hp}$ concentration and stenotic percentage $(r=0.236, P<$ 0.001). However, there were no significant correlations between these variables for either the CAD or control group alone (data not shown).

There was a significant correlation between $\mathrm{Hp}$ and CRP concentrations in the CAD group $(r=0.386, P<0.001)$, but not in the control group $(r=0.197, P=0.112)$.

Simple logistic regression analysis revealed that CAD was significantly associated with high $\mathrm{Hp}$ concentrations, male sex, hypertension, diabetes mellitus, smoking, low HDL
Table 1. Baseline characteristics of study participants $(\mathrm{N}=$ 442).

\begin{tabular}{|c|c|c|c|c|}
\hline & & CAD & Control & \\
\hline \multicolumn{2}{|l|}{ Variables } & $(n=359)$ & $(n=83)$ & $P$ Value \\
\hline \multicolumn{2}{|l|}{ Age (years) } & $68.6 \pm 8.6$ & $69.0 \pm 7.8$ & 0.756 \\
\hline \multicolumn{2}{|l|}{ Male sex } & $325(90.5)$ & $61(73.5)$ & $<0.001^{*}$ \\
\hline \multicolumn{2}{|l|}{ BMI $\left(\mathrm{kg} / \mathrm{m}^{2}\right)$} & $25.36 \pm 3.50$ & $25.99 \pm 3.34$ & 0.168 \\
\hline \multicolumn{2}{|l|}{ Hypertension } & $232(64.6)$ & $31(37.8)$ & $<0.001^{*}$ \\
\hline \multicolumn{2}{|l|}{ Diabetes Mellitus } & $96(26.7)$ & $7(8.5)$ & $<0.001^{*}$ \\
\hline \multicolumn{2}{|l|}{ Smoking } & $184(51.4)$ & $25(30.9)$ & $0.001^{*}$ \\
\hline \multicolumn{2}{|l|}{ Drinking } & $114(31.8)$ & $19(23.5)$ & 0.142 \\
\hline \multicolumn{2}{|l|}{ Hemoglobin (g/dL) } & $13.0 \pm 1.8$ & $13.1 \pm 1.7$ & 0.737 \\
\hline \multicolumn{2}{|l|}{$\mathrm{CRP}(\mathrm{mg} / \mathrm{L})$} & $0.88 \pm 1.67$ & $0.62 \pm 1.60$ & $<0.001^{*}$ \\
\hline \multirow[t]{4}{*}{ Lipid profile (mg/dL) } & TC & $192.9 \pm 45.8$ & $189.1 \pm 38.7$ & 0.477 \\
\hline & TG & $161.9 \pm 112.0$ & $157.3 \pm 154.9$ & 0.060 \\
\hline & $\mathrm{HDL}$ & $37.5 \pm 11.7$ & $40.6 \pm 12.3$ & $0.030^{*}$ \\
\hline & LDL & $124.5 \pm 44.2$ & $112.4 \pm 34.9$ & $0.020^{*}$ \\
\hline \multirow[t]{2}{*}{ Prior $\mathrm{Ml}^{\mathrm{a}}$} & Yes & $144(40.1)$ & ND & NA \\
\hline & No & 215 (59.9) & ND & \\
\hline \multirow[t]{3}{*}{$\begin{array}{l}\text { Number of diseased } \\
\text { vessels }\end{array}$} & One & $105(29.2)$ & ND & NA \\
\hline & Two & $98(27.3)$ & ND & \\
\hline & Three & $156(43.5)$ & ND & \\
\hline \multirow[t]{4}{*}{ Medications } & ARB & $101(28.1)$ & $15(18.1)$ & 0.062 \\
\hline & ACEI & $142(39.6)$ & $20(24.1)$ & $0.008^{*}$ \\
\hline & Statin & $94(26.2)$ & $16(19.3)$ & 0.190 \\
\hline & Beta-blocker & $60(16.7)$ & $11(13.3)$ & 0.439 \\
\hline \multicolumn{2}{|l|}{ Hp concentration (ng/mL) } & $262.4 \pm 144.2$ & $176.0 \pm 86.7$ & $<0.001^{*}$ \\
\hline \multirow[t]{3}{*}{ Hp phenotype } & $1 / 1$ & $27(7.5)$ & $6(7.2)$ & 0.957 \\
\hline & $2-1$ & $145(40.4)$ & $35(42.2)$ & \\
\hline & $2 / 2$ & $187(52.1)$ & $42(50.6)$ & \\
\hline
\end{tabular}

Data are presented as mean \pm standard deviation or number (percent).

ACEl: angiotensin converting enzyme inhibitor; ARB: angiotensin receptor blocker; BMI: body mass index; CAD: coronary artery disease; CRP, C-reactive protein; HDL: high-density lipoprotein; Hp: haptoglobin; LDL: low-density lipoprotein; MI: myocardial infarction; NA: not applicable; ND: not determined; TC: total cholesterol; TG: triglyceride.

a greater than or equal to three months before the start of the study.

* Indicates a statistically significant between group difference $(P<0.05)$. doi: 10.1371/journal.pone.0076817.t001

concentrations, and high LDL concentrations (all $P<0.05$, Table 3). Subsequent multiple logistic regression analysis revealed that $\mathrm{CAD}$ was significantly associated with high $\mathrm{Hp}$ concentrations, male sex, hypertension, diabetes mellitus, and high LDL concentrations (all $P<0.05$, Table 3 ). The C-statistic for the multiple logistic regression model was $0.805(95 \% \mathrm{Cl}$ : 0.757 to $0.853, P<0.001$ ); Meanwhile, the C-statistic for the simple logistic regression model was ranged from 0.582 (95\% $\%$ : 0.508 to $0.652, P=0.023$ ) to 0.662 (95Cl: 0.604 to $0.720, P<0.001)$ for those variables selected into multiple logistic regression analysis. For the simple logistic regression model, the -2In likelihood ratio was 396.3 with the inclusion of $\mathrm{Hp}$ concentration as a variable; meanwhile, the -2ln likelihood ratio was ranged from 403.3 to 419.6 for those variables selected into multiple logistic regression model. For the multiple 


\section{Figure 1}

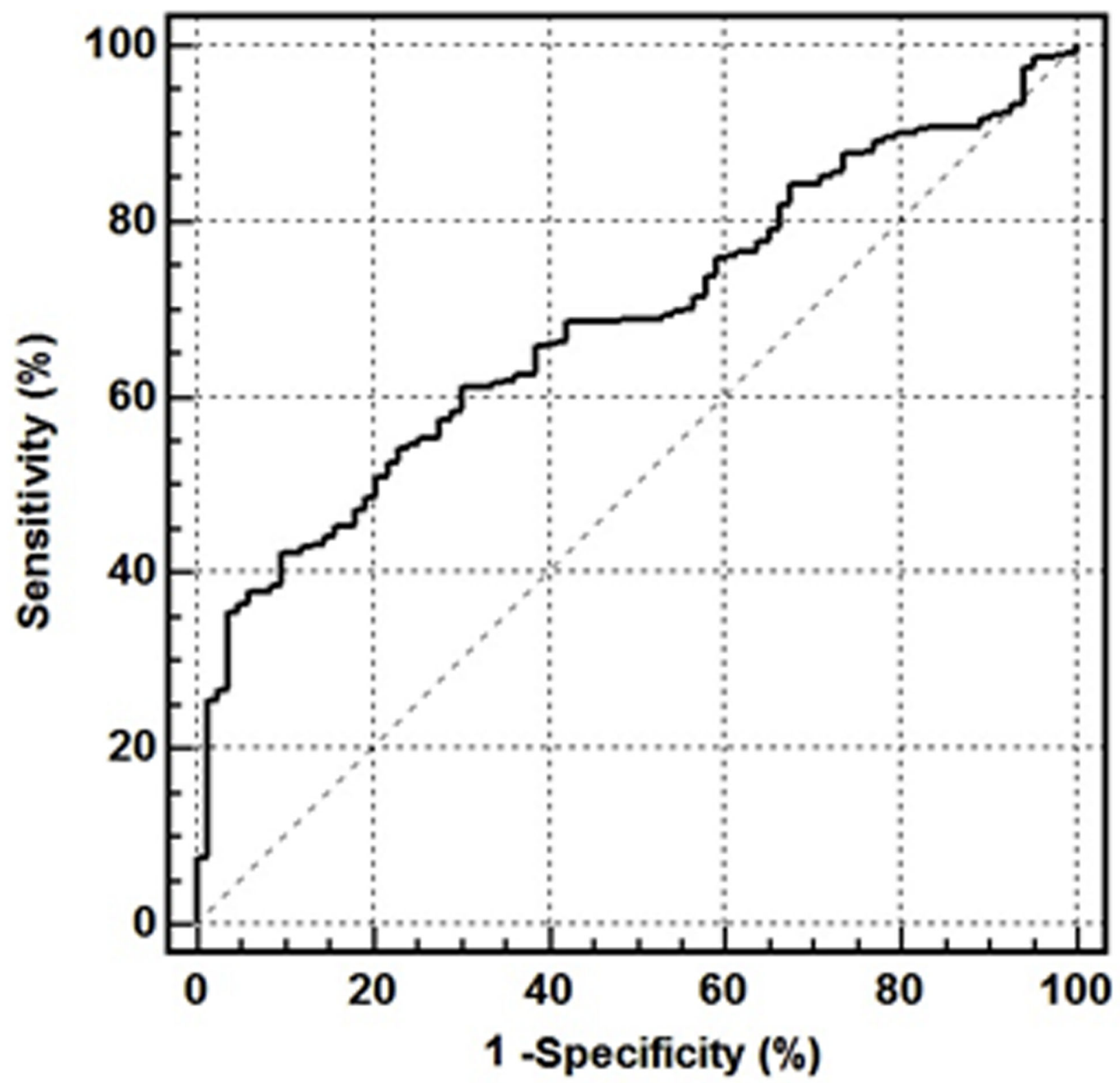

Figure 1. Receiver operating characteristic (ROC) curve for the optimal haptoglobin concentration cut-off for identifying the presence / absence of coronary artery disease.

doi: 10.1371/journal.pone.0076817.g001

logistic regression model, the -2 In likelihood ratio was 354.2 without the inclusion of $\mathrm{Hp}$ concentration as a variable and 327.8 with the inclusion of $\mathrm{Hp}$ concentration as a variable.

\section{Discussion}

To our knowledge, this is the first study to examine plasma $\mathrm{Hp}$ concentrations in patients with CAD. Of note, we found that 
Table 2. Comparison of participants' characteristics by coronary artery disease status and haptoglobin concentration (low or high).

\begin{tabular}{|c|c|c|c|c|c|c|c|}
\hline \multirow[b]{3}{*}{ Variable } & & \multicolumn{3}{|l|}{ CAD } & \multicolumn{3}{|l|}{ Control } \\
\hline & & \multirow{2}{*}{$\begin{array}{l}\text { Low, Hp } \leq 288.4 \mathrm{ng} / \mathrm{mL} \text { ( } \mathrm{n} \\
=208 \text { ) }\end{array}$} & \multicolumn{2}{|c|}{ High, Hp >288.4 ng/mL (n } & \multicolumn{3}{|c|}{ Low, Hp $\leq 288.4$ ng/mL (n High, Hp >288.4 ng/mL } \\
\hline & & & $=151)$ & $\boldsymbol{P}$ & $=75)$ & $(n=8)$ & $\boldsymbol{P}$ \\
\hline Age (years) & & $68.52 \pm 8.00$ & $68.8 \pm 9.5$ & 0.777 & $69.36 \pm 7.82$ & $65.13 \pm 7.22$ & 0.147 \\
\hline Male sex & & $190(52.9)$ & $135(41.5)$ & 0.535 & $53(86.9)$ & $8(13.1)$ & 0.102 \\
\hline BMI $\left(\mathrm{kg} / \mathrm{m}^{2}\right)$ & & $25.34 \pm 3.40$ & $25.40 \pm 3.64$ & 0.865 & $26.04 \pm 3.29$ & $25.50 \pm 4.07$ & 0.745 \\
\hline Hypertension & & $129(55.6)$ & $103(44.4)$ & 0.249 & $30(96.8)$ & $1(3.2)$ & 0.248 \\
\hline Diabetes Mellitus & & $55(57.3)$ & $41(42.7)$ & 0.881 & $6(85.7)$ & $1(14.3)$ & 0.527 \\
\hline Smoking & & $101(54.9)$ & $83(45.1)$ & 0.248 & $24(96.0)$ & $1(4.0)$ & 0.424 \\
\hline Drinking & & $64(56.1)$ & $50(43.9)$ & 0.638 & $18(94.7)$ & $1(5.3)$ & 0.673 \\
\hline Hemoglobin (g/dL) & & $13.24 \pm 1.59$ & $12.7 \pm 2.1$ & $0.013^{*}$ & $13.26 \pm 1.55$ & $11.57 \pm 2.08$ & $0.010^{*}$ \\
\hline CRP (mg/L) & & $0.63 \pm 1.37$ & $1.22 \pm 1.97$ & $<0.001^{*}$ & $0.65 \pm 1.69$ & $0.35 \pm 0.26$ & 0.365 \\
\hline \multirow[t]{4}{*}{ Lipid profile (mg/dL) } & $\mathrm{TC}$ & $194.83 \pm 45.34$ & $190.3 \pm 46.5$ & 0.355 & $189.24 \pm 37.72$ & $187.38 \pm 50.01$ & 0.898 \\
\hline & TG & $169.54 \pm 127.62$ & $151.3 \pm 85.0$ & 0.129 & $163.00 \pm 160.57$ & $103.63 \pm 69.77$ & 0.072 \\
\hline & $\mathrm{HDL}$ & $37.79 \pm 12.99$ & $37.1 \pm 9.7$ & 0.572 & $40.47 \pm 12.82$ & $42.13 \pm 6.69$ & 0.562 \\
\hline & LDL & $126.73 \pm 44.28$ & $121.5 \pm 44.0$ & 0.273 & $112.77 \pm 34.35$ & $109.13 \pm 41.87$ & 0.752 \\
\hline Prior MI & & $79(54.9)$ & $65(45.1)$ & 0.334 & ND & ND & NA \\
\hline \multirow[t]{3}{*}{$\begin{array}{l}\text { Number of diseased } \\
\text { vessels }\end{array}$} & One & $63(60.0)$ & $42(40.0)$ & 0.846 & ND & ND & NA \\
\hline & Two & $57(58.2)$ & $41(41.8)$ & & ND & ND & \\
\hline & Three & $88(56.4)$ & $68(43.6)$ & & ND & ND & \\
\hline Stenotic percentage ${ }^{b}$ & & $90.80 \pm 12.13$ & $90.25 \pm 12.34$ & 0.609 & $5.67 \pm 11.69$ & $N D^{c}$ & NA \\
\hline Hp concentration (ng/mL) & & $165.25 \pm 72.85$ & $396.3 \pm 105.6$ & $<0.001$ & $159.37 \pm 71.62$ & $332.23 \pm 53.67$ & $<0.001$ \\
\hline \multirow[t]{3}{*}{ Hp phenotype } & $1-1$ & $25(92.6)$ & $2(7.4)$ & $<0.001^{\star}$ & $6(100)$ & $0(0)$ & 1.000 \\
\hline & $2-1$ & $55(37.9)$ & $90(62.1)$ & & $31(88.6)$ & $4(11.4)$ & \\
\hline & $2-2$ & $128(68.4)$ & $59(31.6)$ & & $38(90.5)$ & $4(9.5)$ & \\
\hline \multirow[t]{4}{*}{ Medications } & ARB & $54(53.5)$ & $47(46.5)$ & 0.283 & $13(86.7)$ & $2(13.3)$ & 0.631 \\
\hline & ACEI & $82(57.7)$ & $60(42.3)$ & 0.952 & $18(90.0)$ & $2(10.0)$ & 1.000 \\
\hline & Statin & $51(54.3)$ & $43(45.7)$ & 0.400 & $15(93.8)$ & $1(6.3)$ & 1.000 \\
\hline & Beta-blocker & $32(53.3)$ & $28(46.7)$ & 0.428 & $10(90.9)$ & $1(9.1)$ & 1.000 \\
\hline
\end{tabular}

Data are presented as mean \pm standard deviation or number (percent).

ACEI: angiotensin converting enzyme inhibitor; ARB: angiotensin receptor blocker; BMI: body mass index; CAD: coronary artery disease; CRP: C-reactive protein; HDL: high-density lipoprotein; Hp: haptoglobin; LDL: low-density lipoprotein; MI: myocardial infarction; NA: not applicable; ND: not determined; TC: total cholesterol; TG: triglyceride.

a. greater than or equal to three months before the start of the study

b. The stenotic percentage was the percent stenosis of the most affected artery.

c. The stenotic percentage was equivalent to zero for all the patients in the control group with a high $\mathrm{Hp}$ concentration.

*. Indicates a significant within group difference in Hp concentrations $(P<0.05)$.

doi: 10.1371/journal.pone.0076817.t002

plasma $\mathrm{Hp}$ concentrations were significantly higher in participants with CAD compared with participants who did not have $\mathrm{CAD}$, and that high plasma $\mathrm{Hp}$ concentrations were independently associated with CAD. We did not find any between group differences in the distribution of Hp phenotypes.

As already noted, plasma $\mathrm{Hp}$ concentrations are known to be increased during inflammation, and indeed by a number of other physiological processes / states, including hemolysis, ineffective erythropoiesis, liver disease, and late pregnancy [22]. Our finding that plasma $\mathrm{Hp}$ concentrations were significantly increased in participants with CAD is consistent with a previous report that plasma concentrations of the soluble form of CD163 are elevated in patients with CAD [23]. The current finding is also in keeping with our previously reported finding that plasma $\mathrm{Hp}$ concentrations are increased in patients with abdominal aortic aneurysm [19]. We suggest that the increased plasma $\mathrm{Hp}$ concentrations in CAD may be a regulatory response to atherosclerotic progression. Hp may also play a proatherogenic role, as suggested by the recently reported finding that $\mathrm{Hp}$ acts as a chemoattractant to pre-B lymphocytes and monocytes in inflammatory adipose tissue [24].

Of note, we found that plasma Hp concentrations, along with traditional risk factors such as hypertension, diabetes, smoking, and LDL concentration, were a significant predictor of CAD. A number of investigators have previously attempted to identify inflammatory biomarkers of CAD. Indeed, in a systematic review, Hamirani and colleagues reported that concentrations 
Table 3. Factors associated with coronary artery disease: Simple and multiple logistic regression analyses.

\begin{tabular}{|c|c|c|c|c|c|}
\hline \multicolumn{2}{|l|}{ Variable } & \multicolumn{2}{|c|}{ Simple Logistic Regression } & \multicolumn{2}{|c|}{ Multiple Logistic Regression } \\
\hline & & OR (95\% Cl) & $P$ value & OR (95\% Cl) & $P$ value \\
\hline \multirow[t]{2}{*}{$\mathrm{Hp}_{\text {concentration }}{ }^{\mathrm{a}}$} & Low & Reference & & Reference & \\
\hline & High & $6.806(3.188,14.531)$ & $<0.001^{*}$ & $5.865(2.672,12.874)$ & $<0.001^{*}$ \\
\hline Age (years) & & $0.962(0.756,1.225)$ & 0.755 & - & \\
\hline \multirow[t]{2}{*}{ Male sex } & Female & Reference & & Reference & \\
\hline & Male & $3.447(1.888,6.294)$ & $<0.001^{*}$ & $3.689(1.683,8.087)$ & $0.001^{*}$ \\
\hline BMI $\left(\mathrm{kg} / \mathrm{m}^{2}\right)$ & & $0.840(0.666,1.059)$ & 0.141 & - & \\
\hline \multirow[t]{2}{*}{ Hypertension } & No & Reference & & Reference & \\
\hline & Yes & $3.029(1.844,4.976)$ & $<0.001^{*}$ & $2.632(1.518,4.564)$ & $0.001^{*}$ \\
\hline \multirow[t]{2}{*}{ Diabetes mellitus } & No & Reference & & Reference & \\
\hline & Yes & $3.911(1.741,8.783)$ & $0.001^{*}$ & $3.300(1.357,8.024)$ & $0.008^{*}$ \\
\hline \multirow[t]{2}{*}{ Smoking } & No & Reference & & Reference & \\
\hline & Yes & $2.369(1.415,3.964)$ & $0.001^{*}$ & $1.654(0.911,3.002)$ & 0.098 \\
\hline \multirow[t]{2}{*}{ Drinking } & No & Reference & & & \\
\hline & Yes & $1.518(0.867,2.658)$ & 0.144 & - & \\
\hline Hemoglobin (g/dL) & & $0.957(0.740,1.237)$ & 0.736 & - & \\
\hline $\mathrm{CRP}(\mathrm{mg} / \mathrm{L})$ & & $1.247(0.854,1.821)$ & 0.254 & - & \\
\hline \multirow[t]{4}{*}{ Lipid profile (mg/dL) } & TC & $1.094(0.855,1.400)$ & 0.476 & - & \\
\hline & TG & $1.041(0.808,1.341)$ & 0.754 & - & \\
\hline & $\mathrm{HDL}$ & $0.785(0.625,0.984)$ & $0.036^{*}$ & $0.966(0.753,1.240)$ & 0.786 \\
\hline & LDL & $1.371(1.049,1.792)$ & $0.021^{*}$ & $1.480(1.096,1.997)$ & $0.010^{*}$ \\
\hline \multirow[t]{3}{*}{ Hp phenotype } & $1-1$ & Reference & & & \\
\hline & $2-1$ & $0.921(0.353,2.401)$ & 0.866 & - & \\
\hline & $2-2$ & $0.989(0.384,2.548)$ & 0.982 & - & \\
\hline
\end{tabular}

The ORs for continuous variables are per standard deviation increase.

BMI: body mass index; Cl: confidence interval; CRP: C-reactive protein; HDL: high-density lipoprotein; Hp: haptoglobin; LDL: low-density lipoprotein; OR: odds ratio; TC: total cholesterol; TG: triglyceride.

High $\mathrm{Hp}$ concentration, $\mathrm{Hp}>288.4 \mathrm{ng} / \mathrm{mL}$; Low Hp concentration, $\mathrm{Hp} \leq 288.4 \mathrm{ng} / \mathrm{mL}$.

a. High $\mathrm{Hp}$ concentration, $\mathrm{Hp}>288.4 \mathrm{ng} / \mathrm{mL}$; Low Hp concentration, $\mathrm{Hp} \leq 288.4 \mathrm{ng} / \mathrm{mL}$.

*. Indicates a significant association $(P<0.05)$.

doi: 10.1371/journal.pone.0076817.t003

of a number of inflammatory mediators, including CRP, fibrinogen, metallic metalloproteinase- 9 , monocyte chemotactic protin-1, resistin, lipoprotein-associated phospholipase A2, interleukin-6, tumor necrosis factor-alpha, and beta-fibroblast growth factor, were positively correlated with atherosclerosis [25]. Unfortunately, these relationships disappeared after correction for traditional risk factors of CAD [25]. In contrast, we found that plasma $\mathrm{Hp}$ concentration remained a significant independent predictor of CAD after controlling for other variables in multivariate analysis. Hence, assessing plasma $\mathrm{Hp}$ concentrations, along with other factors, may prove to be of use in the future for the diagnosis / monitoring of CAD.

Interestingly, we did not find any significant relationship between $\mathrm{Hp}$ phenotype and CAD. This could be considered somewhat surprising given the evidence from other studies that the Hp 2-2 phenotype may be associated with cardiovascular disease. Indeed, individuals with the Hp 2-2 phenotype appear to have reduced clearance of the macrophage- $\mathrm{Hp}-\mathrm{Hb}$ complex, which affects iron deposition, oxidative stress, and active macrophage accumulation [26]. These changes would be consistent with an increased risk of atherosclerotic cardiovascular disease. Other studies have reported that the
Hp 2-2 phenotype is associated with an increased risk of peripheral arterial occlusive disease [27], diabetic nephropathy [28], acute myocardial infarction, stroke, and heart failure [12]. Indeed, we have also found that the Hp 2-2 phenotype is more common among patients with abdominal aortic aneurysm compared with patients who do not have this condition [19]. However, the findings from a number of other studies do not support an association between $\mathrm{Hp}$ phenotype and cardiovascular disease [16,29,30]. Indeed, Carter et al. [22] concluded that even though biological and functional differences may exist between $\mathrm{Hp}$ phenotypes, the clinical associations with these differences may be marginal. Of note, we found that a significantly higher proportion of participants with low $\mathrm{Hp}$ concentrations had the $\mathrm{Hp}$ 1-1 phenotype compared with those who had high $\mathrm{Hp}$ concentrations. This finding is consistent with $\mathrm{Hp} \mathrm{1-1} \mathrm{having} \mathrm{the} \mathrm{strongest} \mathrm{affinity} \mathrm{for}$ binding $\mathrm{Hp}$ [10]. Given the purported link between $\mathrm{Hp}$ and $C A D$, one may have surmised that patients with the $\mathrm{Hp} \mathrm{1-1}$ phenotype would have a decreased risk of CAD because of their lower plasma Hp concentrations. However, no such decreased risk was identified in our regression analysis, presumably because a large proportion of participants with low 
Hp concentrations had the Hp 2-2 phenotype. Taken together, our findings do not support the existence of an association between $\mathrm{Hp}$ phenotype and CAD.

We found that plasma $\mathrm{Hp}$ concentrations were significantly associated with the extent of stenosis for the overall study population, but not the CAD or control group alone. However, the strength of correlation was not particularly high $(r=0.236)$. This weak positive correlation, and indeed the lack of any correlation between $\mathrm{Hp}$ concentration and the extent of stenosis among participants with CAD, is perhaps not unsurprising given that $\mathrm{Hp}$ is a global marker of inflammation and is not specific for CAD.

Our study has several limitations that warrant acknowledgment. Of note, the control group of participants was recruited from a hospital-based population and was relatively small in size. Further, all participants in the control group had positive thallium myocardial perfusion scans. Furthermore, several differences in baseline characteristics also existed between study participants in the two groups. These cohort characteristics and differences may have introduced bias and affected the results of our study to some extent. Hence, a more

\section{References}

1. Go AS, Mozaffarian D, Roger VL, Benjamin EJ, Berry JD et al. (2013) Executive summary: heart disease and stroke statistics--2013 update: a report from the American Heart Association. Circulation127: 143-152. doi:10.1161/CIR.0b013e318282ab8f. PubMed: 23283859.

2. Hansson GK (2005) Inflammation, atherosclerosis, and coronary artery disease. N Engl J Med 352: 1685-1695. doi:10.1056/NEJMra043430. PubMed: 15843671.

3. Wilson PW (2008) Evidence of systemic inflammation and estimation of coronary artery disease risk: a population perspective. Am J Med 121: S15-S20. doi:10.1016/j.amjmed.2008.01.031. PubMed: 18926165.

4. McPherson R, Davies RW (2012) Inflammation and coronary artery disease: insights from genetic studies. Can J Cardiol 28: 662-666. doi: 10.1016/j.cjca.2012.05.014. PubMed: 22902153.

5. Morimatsu M, Syuto B, Shimada N, Fujinaga T, Yamamoto $S$ et al. (1991) Isolation and characterization of bovine haptoglobin from acute phase sera. J Biol Chem 266: 11833-11837. PubMed: 1904872.

6. Bowman $\mathrm{BH}$, Kurosky A (1982) Haptoglobin: the evolutionary product of duplication, unequal crossing over, and point mutation. Adv Hum Genet 12: 189-454. 6751044.

7. Kristiansen M, Graversen JH, Jacobsen C, Sonne O, Hoffman HJ et al. (2001) Identification of the haemoglobin scavenger receptor. Nature 409: 198-201. doi:10.1038/35051594. PubMed: 11196644.

8. Tseng CF, Lin CC, Huang HY, Liu HC, Mao SJ (2004) Antioxidant role of human haptoglobin. Proteomics 4: 2221-2228. doi:10.1002/pmic. 200300787. PubMed: 15274115

9. Langlois MR, Delanghe JR (1996) Biological and clinical significance of haptoglobin polymorphism in humans. Clin Chem 42: 1589-1600. PubMed: 8855140

10. Melamed-Frank M, Lache O, Enav BI, Szafranek T, Levy NS et al. (2001) Structure-function analysis of the antioxidant properties of haptoglobin. Blood 98: 3693-3698. doi:10.1182/blood.V98.13.3693. PubMed: 11739174.

11. Levy AP, Levy JE, Kalet-Litman S, Miller-Lotan R, Levy NS et al. (2007) Haptoglobin genotype is a determinant of iron, lipid peroxidation, and macrophage accumulation in the atherosclerotic plaque. Arterioscler Thromb Vasc Biol 27: 134-140. doi:10.1161/01.ATV. 0000251020.24399.a2. PubMed: 17068284.

12. Holme I, Aastveit AH, Hammar N, Jungner I, Walldius G (2009) Haptoglobin and risk of myocardial infarction, stroke, and congestive heart failure in 342,125 men and women in the Apolipoprotein MOrtality RISk study (AMORIS). Ann Med 41: 522-532. doi: 10.1080/07853890903089453. PubMed: 19657769.

13. Levy AP, Hochberg I, Jablonski K, Resnick HE, Lee ET et al. (2002) Haptoglobin phenotype is an independent risk factor for cardiovascular disease in individuals with diabetes: The Strong Heart Study. J Am Coll Cardiol 40: 1984-1990. doi:10.1016/S0735-1097(02)02534-2. PubMed: 12475459. appropriately controlled study is warranted to confirm the findings reported herein.

In summary, we have reported that plasma $\mathrm{Hp}$ concentrations are significantly increased in patients with CAD compared with patients who do not have CAD, and that plasma $\mathrm{Hp}$ concentrations are independently associated with CAD. We did not detect any association between $\mathrm{Hp}$ phenotype and CAD. Further studies are needed to better elucidate the apparent link between $\mathrm{Hp}$ and $\mathrm{CAD}$, and to examine the potential diagnostic / monitoring significance of such a link. Refinement / simplification of the methodology for assessing plasma $\mathrm{Hp}$ concentration is also essential for wider clinical application.

\section{Author Contributions}

Conceived and designed the experiments: JPP. Performed the experiments: CWL TMC JPP. Analyzed the data: CWL JPP. Contributed reagents/materials/analysis tools: TMC CPL JPP. Wrote the manuscript: CWL JPP.

14. Roguin A, Koch W, Kastrati A, Aronson D, Schomig A et al. (2003) Haptoglobin genotype is predictive of major adverse cardiac events in the 1-year period after percutaneous transluminal coronary angioplasty in individuals with diabetes. Diabetes Care 26: 2628-2631. doi:10.2337/ diacare.26.9.2628. PubMed: 12941730 .

15. Suleiman M, Aronson D, Asleh R, Kapeliovich MR, Roguin A et al. (2005) Haptoglobin polymorphism predicts 30-day mortality and heart failure in patients with diabetes and acute myocardial infarction. Diabetes 54: 2802-2806. doi:10.2337/diabetes.54.9.2802. PubMed: 16123372.

16. Levy AP, Larson MG, Corey D, Lotan R, Vita JA et al. (2004) Haptoglobin phenotype and prevalent coronary heart disease in the Framingham offspring cohort. Atherosclerosis 172: 361-365. doi: 10.1016/j.atherosclerosis.2003.10.014. PubMed: 15019547.

17. Liau CY, Chang TM, Pan JP, Chen WL, Mao SJ (2003) Purification of human plasma haptoglobin by hemoglobin-affinity column chromatography. J Chromatogr B Anal Technol Biomed Life Sci 790: 209-216. doi:10.1016/S1570-0232(03)00128-4. PubMed: 12767333.

18. Tseng CF, Huang HY, Yang YT, Mao SJ (2004) Purification of human haptoglobin 1-1, 2-1, and 2-2 using monoclonal antibody affinity chromatography. Protein Expr Purif 33: 265-273. doi:10.1016/j.pep. 2003.09.006. PubMed: 14711515.

19. Pan JP, Cheng TM, Shih CC, Chiang SC, Chou SC et al. (2011) Haptoglobin phenotypes and plasma haptoglobin levels in patients with abdominal aortic aneurysm. J Vasc Surg 53: 1189-1194. doi:10.1016/ j.jvs.2010.10.122. PubMed: 21296538.

20. Austen WG, Edwards JE, Frye RL, Gensini GG, Gott VL et al. (1975) A reporting system on patients evaluated for coronary artery disease. Report of the Ad Hoc Committee for Grading of Coronary Artery Disease, Council on Cardiovascular Surgery, American Heart Association. Circulation 51: 5-40. doi:10.1161/01.CIR.51.4.5. PubMed: 1116248.

21. Cheng TM, Pan JP, Lai ST, Kao LP, Lin HH et al. (2007) Immunochemical property of human haptoglobin phenotypes: determination of plasma haptoglobin using type-matched standards. Clin Biochem 40: 1045-1056. doi:10.1016/j.clinbiochem.2007.04.018. PubMed: 17583688.

22. Carter K, Worwood M (2007) Haptoglobin: a review of the major allele frequencies worldwide and their association with diseases. Int $\mathrm{J}$ Lab Hematol 29: 92-110. doi:10.1111/j.1751-553X.2007.00898.x. PubMed: 17474882.

23. Aristoteli LP, Møller HJ, Bailey B, Moestrup SK, Kritharides L (2006) The monocytic lineage specific soluble CD163 is a plasma marker of coronary atherosclerosis. Atherosclerosis 184: 342-347. doi:10.1016/ j.atherosclerosis.2005.05.004. PubMed: 15979079.

24. Delanghe JR, Langlois MR, De Buyzere ML (2011) Haptoglobin polymorphism: a key factor in the proatherogenic role of $B$ cells? 
Atherosclerosis 217: 80-82. doi:10.1016/j.atherosclerosis.2011.03.031. PubMed: 21507405.

25. Hamirani YS, Pandey S, Rivera JJ, Ndumele C, Budoff MJ et al. (2008) Markers of inflammation and coronary artery calcification: a systematic review. Atherosclerosis 201: 1-7. doi:10.1016/j.atherosclerosis. 2008.04.045. PubMed: 18561934.

26. Moreno PR, Purushothaman KR, Purushothaman M, Muntner P, Levy NS et al. (2008) Haptoglobin genotype is a major determinant of the amount of iron in the human atherosclerotic plaque. J Am Coll Cardiol 52: 1049-1051. doi:10.1016/j.jacc.2008.06.029. PubMed: 18848136.

27. Delanghe J, Langlois M, Duprez D, De Buyzere M, Clement D (1999) Haptoglobin polymorphism and peripheral arterial occlusive disease.
Atherosclerosis 145: 287-292. doi:10.1016/S0021-9150(99)00079-9. PubMed: 10488955.

28. Levy AP, Roguin A, Hochberg I, Herer P, Marsh S et al. (2000) Haptoglobin phenotype and vascular complications in patients with diabetes. $N$ Engl J Med 343: 969-970. doi:10.1056/ NEJM200009283431313. PubMed: 11012324

29. Staals J, Pieters BM, Knottnerus IL, Rouhl RP, van Oostenbrugge RJ et al. (2008) Haptoglobin polymorphism and lacunar stroke. Curr Neurovasc Res 5: 153-158. doi:10.2174/156720208785425675. PubMed: 18691072.

30. De Bacquer D, De Backer G, Langlois M, Delanghe J, Kesteloot H et al. (2001) Haptoglobin polymorphism as a risk factor for coronary heart disease mortality. Atherosclerosis 157: 161-166. doi:10.1016/ S0021-9150(00)00690-0. PubMed: 11427216 